\title{
Study of Traffic Flow Characteristics for Heterogeneous Traffic
}

\author{
S. Yamuna \\ Rajeev Gandhi Memorial College of Engineering and Technology, Nandyal, Andhra Pradesh.
}

\begin{abstract}
Knowledge of fundamental traffic flow characteristics and vehicle dynamic behavior are essential for operation of transportation system. The fundamental characteristics of speed and flow have been studied. Time-headway distribution of urban heterogeneous traffic was also studied. An appropriate methodology was adopted to collect and extract headway data. The methodology for choice of best fitting statistical distribution to the observed headway data has also been described. The result of the study has shown that, the headways of urban heterogeneous traffic can be modelled for vehicles over a wide range of traffic flow levels. Speed-flow curves for a selected road facility were plotted.
\end{abstract}

\section{INTRODUCTION}

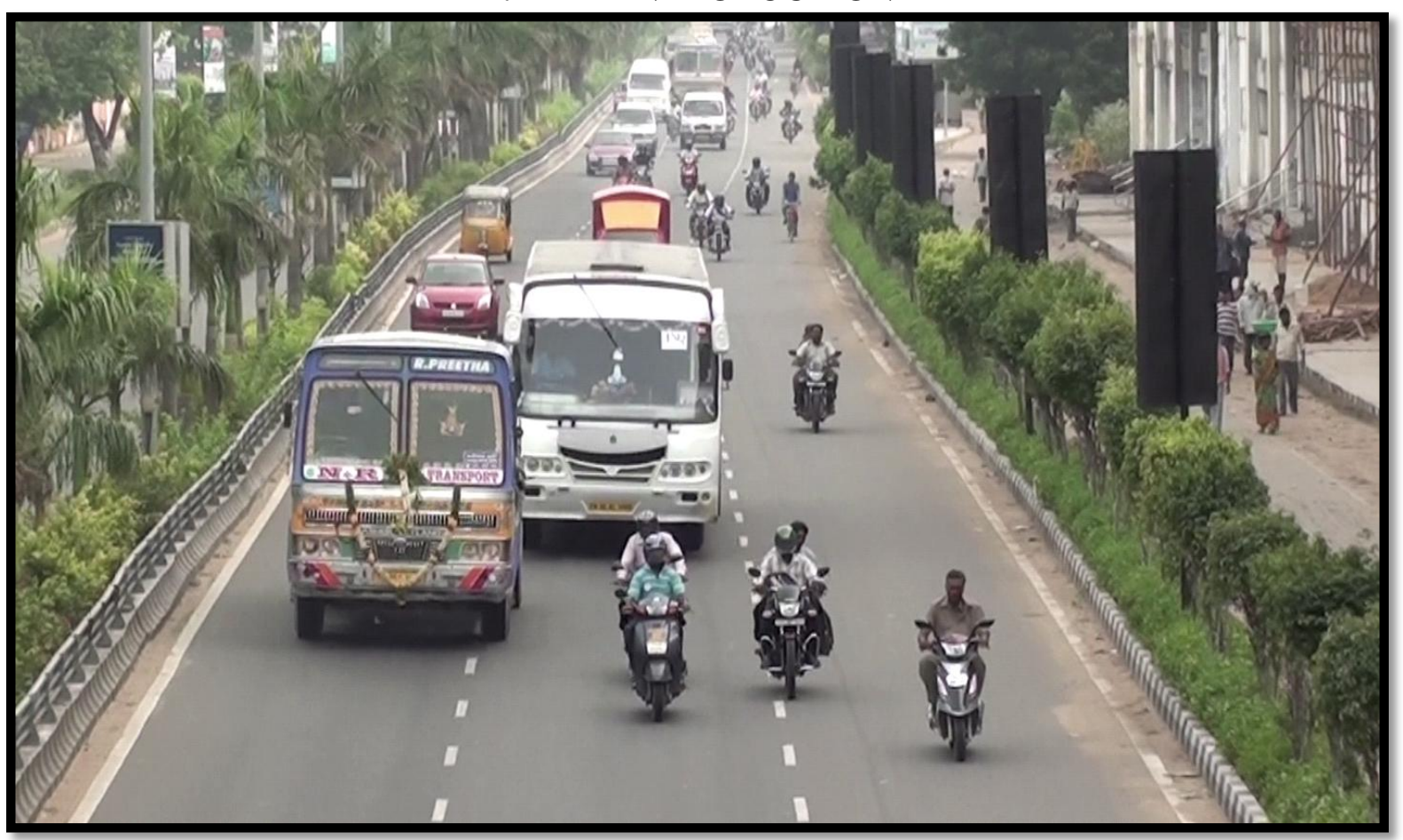

Figure 1: Heterogonous traffic

The traffic condition in India is highly heterogeneous in nature and vehicles do not follow lane discipline which makes it difficult to study and analyze traffic flow characteristics. Traffic flow theories seek to describe in a mathematical way the interactions between vehicles and operators. To understand traffic flow, relationships have been established between the two main characteristics: flow and velocity.

Velocity or Speed is the rate of movement of traffic and usually expressed in kilometer per hour. Speed is one of the important factors directly influencing mobility. Speed of the vehicles on the roadway is affected by drivers behaviour, Physical characteristics of the road, roadside interference, Weather, presence of other vehicles, etc. Speed is the important dynamic character to be studied. Flow or Volume is the number of vehicles passing a specified point during a stated period of time. It is expressed in vehicles per hour. The measurement of traffic volumes is one of the most basic functions of highway planning and management. Traffic volume counts are the most common measure of roadway usage, and they are needed as an input to the majority of traffic engineering analyses.

The headway between vehicles in a traffic stream is of fundamental importance in traffic engineering applications. The time gap between successive vehicle arrivals, namely, time headway on a highway is an important microscopic traffic flow characteristic that affects the safety, level of service, driver behavior and road 
capacity. Understanding time headways and their distributions will enable better management of traffic. It is expressed in seconds.

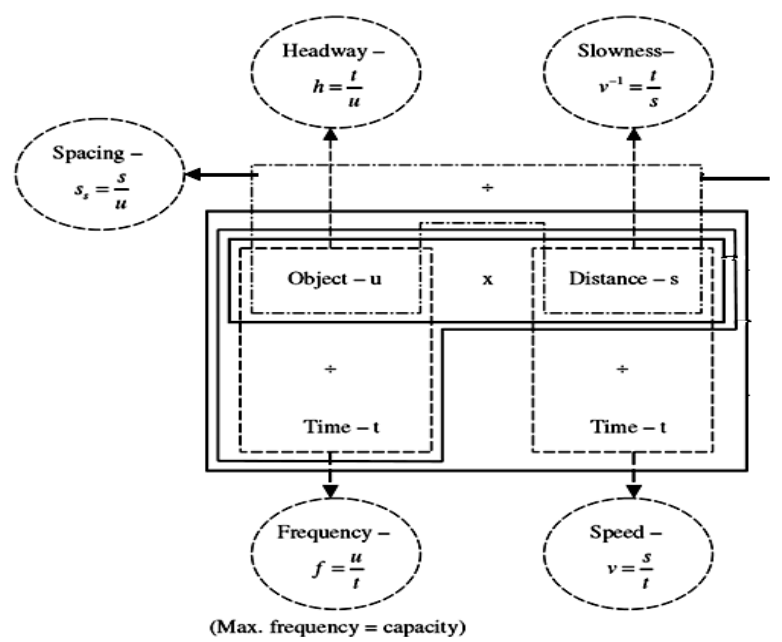

Figure 2: Traffic flow characteristics (Source: May, 1990)

Capacity is defined as maximum hourly volume at which vehicles can reasonably be expected to traverse a point. Capacity is influenced by number of lanes, lane width, number and spacing of access points, shoulder presence and width, gradient of the road, driving population etc. The time period normally used for expressing capacity is the hour. Sometimes it is considered more expedient to bring all the vehicles to a common type, usually the passenger car. The capacity is then expressed in passenger car unit (PCUs) per hour.

\section{LITERATURE REVIEW}

Guidelines for Capacity of Urban Roads in Plain Areas - IRC106 (1990): This code recommends PCU values for various types of vehicles in urban roads and explains level of service criteria for urban roads. Vehicle Class wise Quantification and Headway Analysis under Heterogeneous Traffic (Kanagaraj et al., 2011). This paper aims to develop and analyze class wise time gap and following headway distribution models for different lead-lag pairs in mixed traffic using data from urban roads in Chennai.

Headway distribution of heterogeneous traffic in urban arterials (Arasan and Khosy, 2003). This paper describes an attempt made to study the time-headway distribution of urban heterogeneous traffic over a wide range of flow levels. The importance of a systematic procedure for grouping of headway data through appropriate choice of class interval has been studied. Arasan and Arkathkar (2011) studied traffic flow characteristics on intercity highways using computer simulation. This paper covers data collection and speed-flow relationships for intercity highway.

\section{DATA COLLECTION}

The study site is located along the IT corridor and in front of the INDIRA NAGAR railway station. It is a six-lane, divided urban road where a heterogeneous traffic condition prevails. One way (3 lane road) roadway width is $10 \mathrm{~m}$. The parameters evaluated in this study are the classified count, speed and headway. The data was collected for one hour in the evening (5:00 to 6:00 PM).

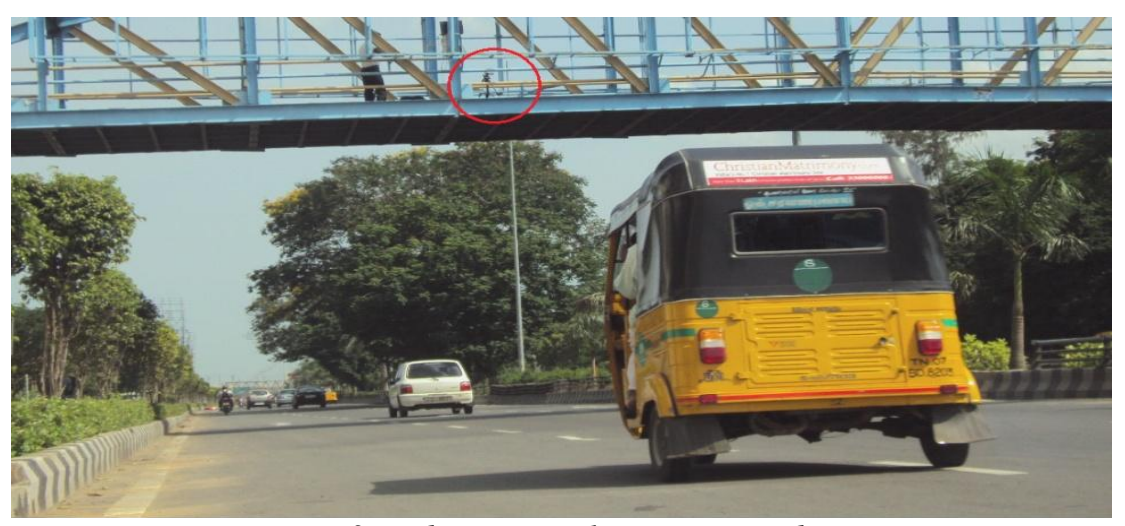

Figure 3: Video camera location at study site 
The volume count of vehicles carried out by recording the video and counting the number by playing the recorded video in the laboratory. Classified count for one minute interval was noted down and was used as the base data for comparison.

Of all the vehicle categories observed, major five vehicle categories were considered to analyze. The following vehicular composition is observed.

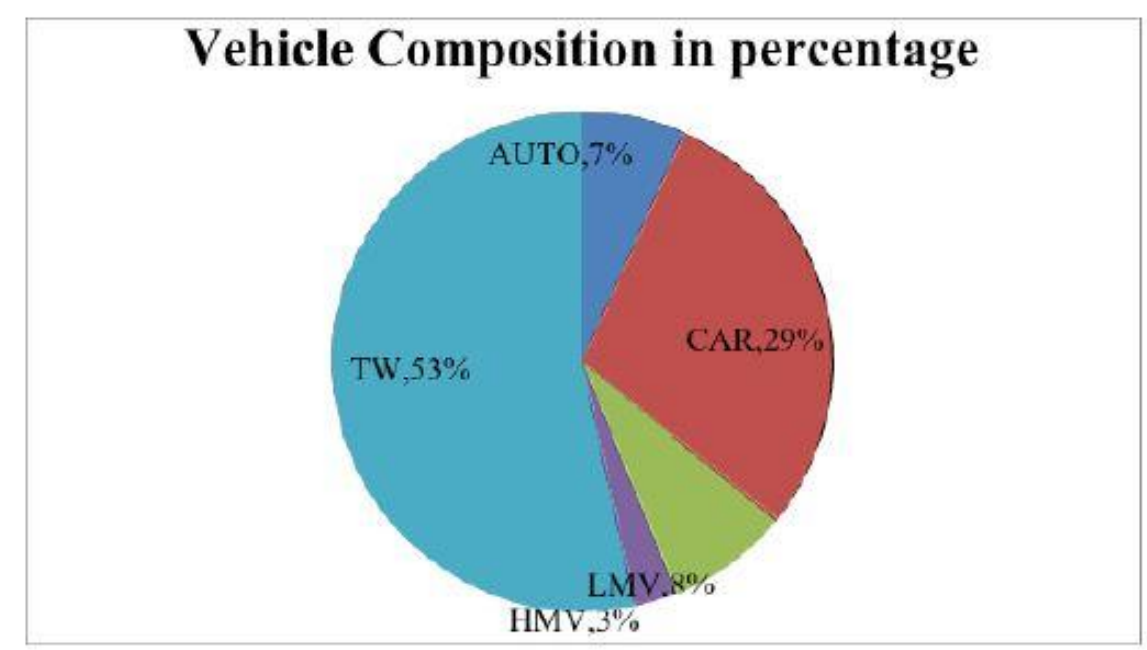

Figure 4: Vehicle composition

IV.

DATA EXTRACTION

Initially, 10 meter length of the road is selected by taking some reference points. The total 10 meter length and width is marked into one meter interval plot on the road. One square meter grids are plotted for 100 square meter using AUTOCAD software. The grid plotted is then transferred on to the obtained field points. The total one hour video data is divided into six 10 minutes interval.

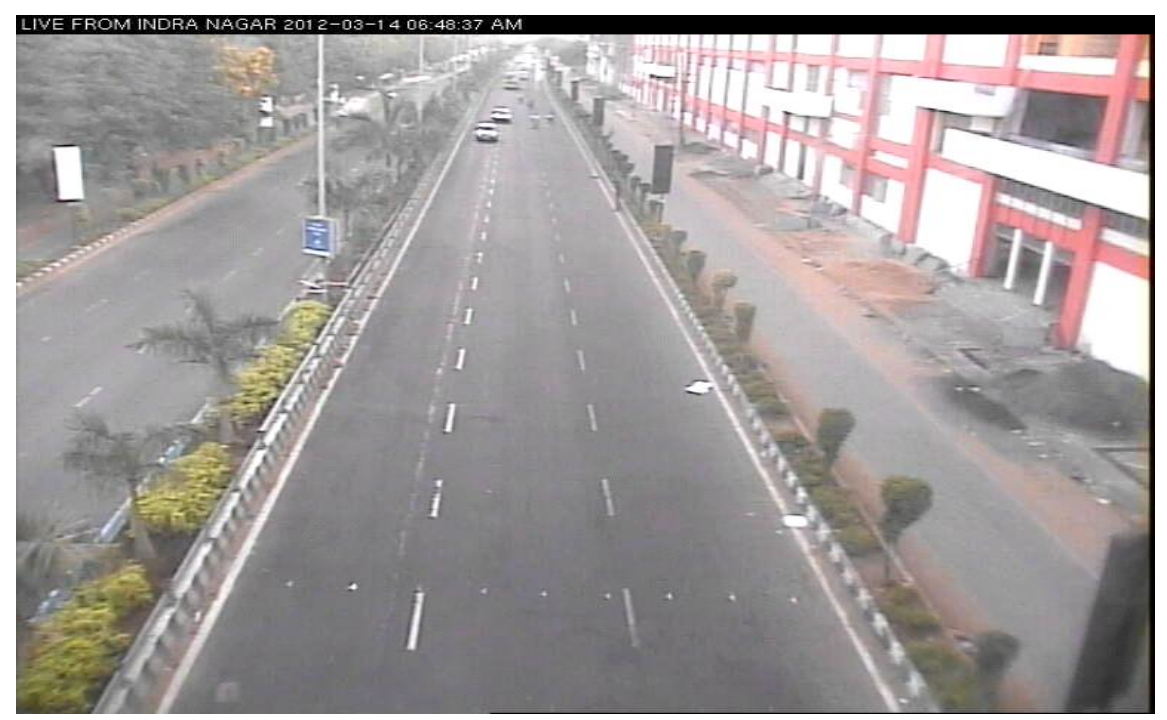

Figure 5: One meter interval marking at the site

The time gaps between successive vehicles can be found by the difference in the frame numbers when successive vehicles pass through a given point. IRFAN view software is used to extract the video into frames. IRFAN view extracts 25 frames for one second. 


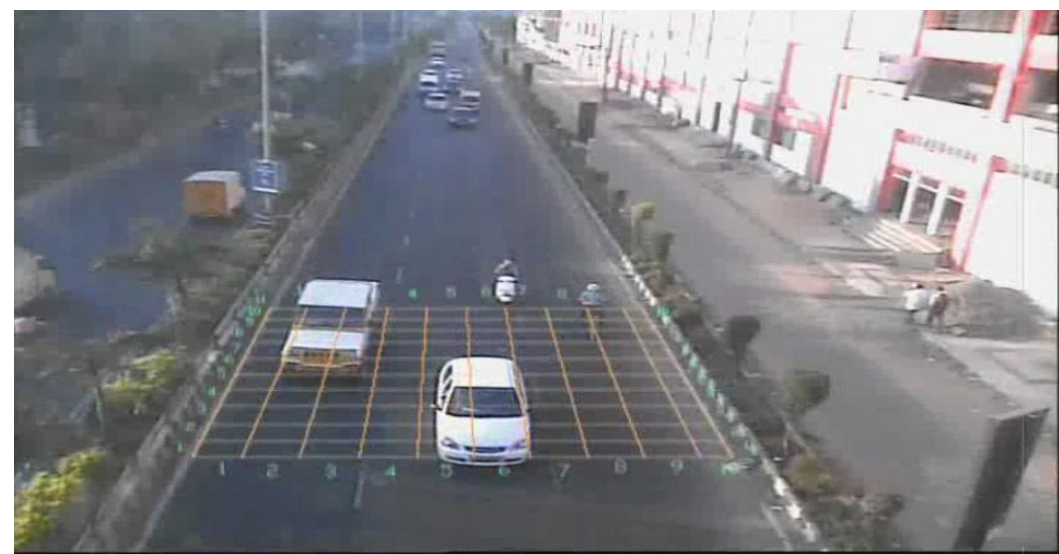

Figure 6: Grid plot overlay on video

Table 1: Data extraction

\begin{tabular}{|c|c|c|c|c|c|c|c|c|c|c|c|}
\hline \multicolumn{5}{|l|}{ Leader } & \multicolumn{5}{|c|}{ Follower } & \multicolumn{2}{|c|}{ Frame no. } \\
\hline \multirow{2}{*}{$\begin{array}{l}\text { Vehicle } \\
\text { Type }\end{array}$} & \multirow[t]{2}{*}{ Lane no. } & \multirow{2}{*}{$\begin{array}{l}\text { Grid } \\
\text { no. }\end{array}$} & \multicolumn{2}{|c|}{ Coordinates } & \multirow[b]{2}{*}{$\begin{array}{l}\text { Vehicle } \\
\text { Type }\end{array}$} & \multirow[b]{2}{*}{$\begin{array}{l}\text { Lane } \\
\text { no. }\end{array}$} & \multirow[b]{2}{*}{$\begin{array}{l}\text { Grid } \\
\text { no. }\end{array}$} & \multicolumn{2}{|c|}{ Coordinates } & \multirow[t]{2}{*}{ Entry } & \multirow[t]{2}{*}{ Exit } \\
\hline & & & Left & Right & & & & Left & Right & & \\
\hline A & 2 & 4 & 311,372 & 347,372 & no & - & - & - & - & 46 & 64 \\
\hline $\mathrm{C}$ & 1 & 5 & 172,364 & 214,363 & no & - & - & - & - & 66 & 83 \\
\hline TW & 2 & 3 & 273,398 & - & A & 2 & 4 & 330,367 & 370,360 & 160 & 176 \\
\hline A & 2 & 4 & 330,367 & 370,360 & LMV & 8 & 8 & 261,327 & 310,330 & 166 & 186 \\
\hline LMV & 2 & 8 & 261,327 & 310,330 & no & - & - & - & - & 183 & 200 \\
\hline TW & 1 & 3 & 184,405 & - & no & - & - & - & - & 200 & 213 \\
\hline
\end{tabular}

A(Auto), C(Car), TW(Two wheeler), LMV(Low motorized vehicles)

\section{Headway}

\section{DATA ANALYSIS}

Primary analysis of headways is performed using the data from the three lane road. Two-wheelers, cars, auto, light motor vehicles and heavy motor vehicles were considered. Further, nearly $24 \%$ of the headways observed were for vehicles in the median side lane, $32 \%$ of the headways in middle lane, and $33 \%$ in kerb lane. $12 \%$ of the vehicle pairs were in-between two lanes, highlighting the imperfect lane discipline present in mixed traffic.

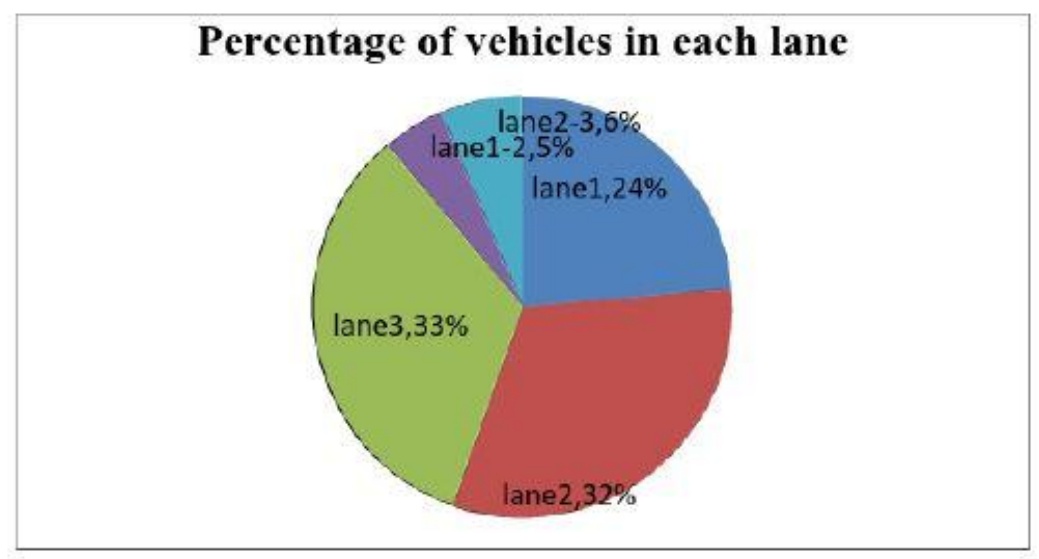

Figure 7: Percentage of vehicles in each lane

Lead-Lag pair headways are extracted from the collected data. 

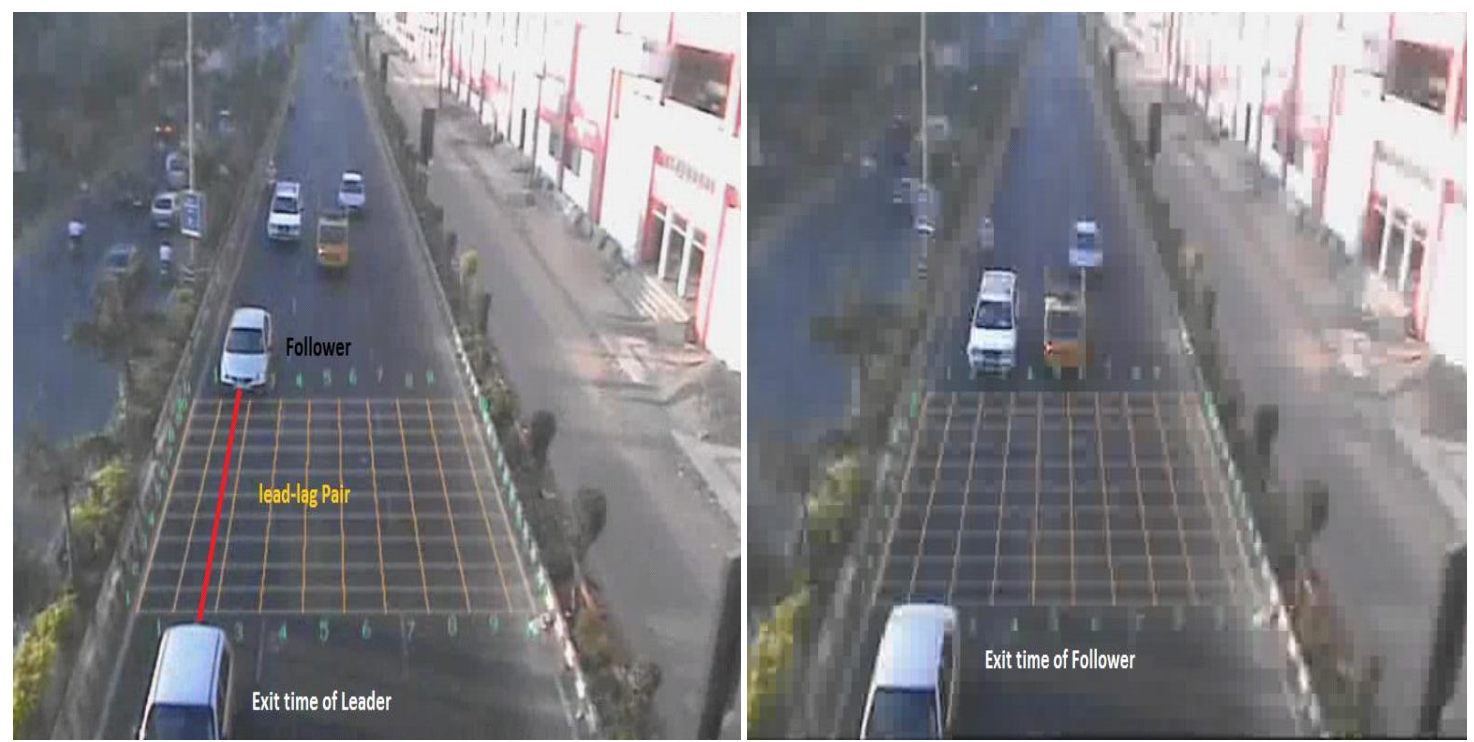

Figure 8: Lead-lag pair

Headway $=($ Exit time of follower-Exit time of leader)/25 (in sec)

Table 2: Headways for Autos as Lead Vehicle

\begin{tabular}{|l|l|l|l|l|l|}
\hline & & \multicolumn{5}{|l|}{ Headways (sec) } \\
\hline S. No. & Lead-Lag Pair & $\begin{array}{l}\text { No. of } \\
\text { observations }\end{array}$ & minimum & Maximum & average \\
\hline 1 & A-C & 12 & 0.96 & 10.76 & 3.893 \\
\hline 2 & A-A & 2 & 0.56 & 14.36 & 7.46 \\
\hline 3 & A-LMV & 6 & 0.96 & 6.36 & 3.873 \\
\hline
\end{tabular}

A(Auto), C(Car), TW(Two wheeler), LMV(Low motorized vehicles)

\section{HEADWAY DISTRIBUTION}

Study of headway distribution is useful in analyzing heterogeneous traffic conditions. The headway distributions across different vehicle class pairs are determined. Hagring (1996) has listed the following requirements that headway distributions need to fulfil: 1 . that they must fit the observed data well, 2. that they must describe driver behaviour adequately and 3 . That they should be useful for prediction.

EASYFIT software is used to fit headway distribution to the observed data. In the present study, a number of other goodness-of-fit measures were also investigated: Kolmogorov-Smirnov test (K-S test), the AndersonDarling statistic and Chi-square test. 25 vehicle pairs have been considered.

\section{Kolmogorov-Smirnov test:}

The Kolmogorov-Smirnov test (K-S test) tries to determine if two datasets differ significantly. The K-S test has the advantage of making no assumption about the distribution of data. (Technically speaking it is nonparametric and distribution free.)

\section{Test for Distributional Adequacy:}

The Kolmogorov-Smirnov test (Chakravart, Laha, and Roy, 1967) is used to decide if a sample comes from a population with a specific distribution. The Kolmogorov-Smirnov (K-S) test is based on the empirical distribution function.

Example: Car-LMV combination

The headways followed log-logisitc distribution 
Table 3: Goodness of fit using K-S test

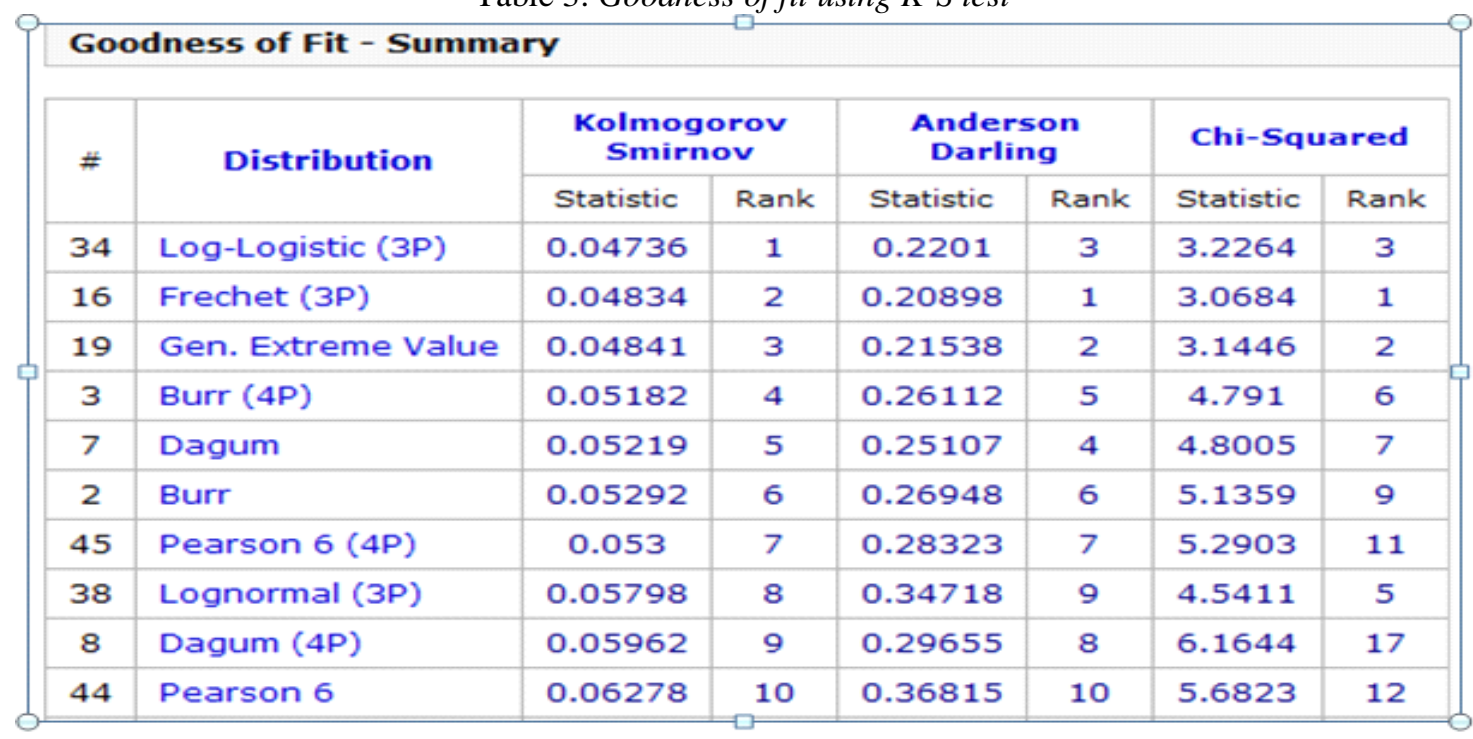

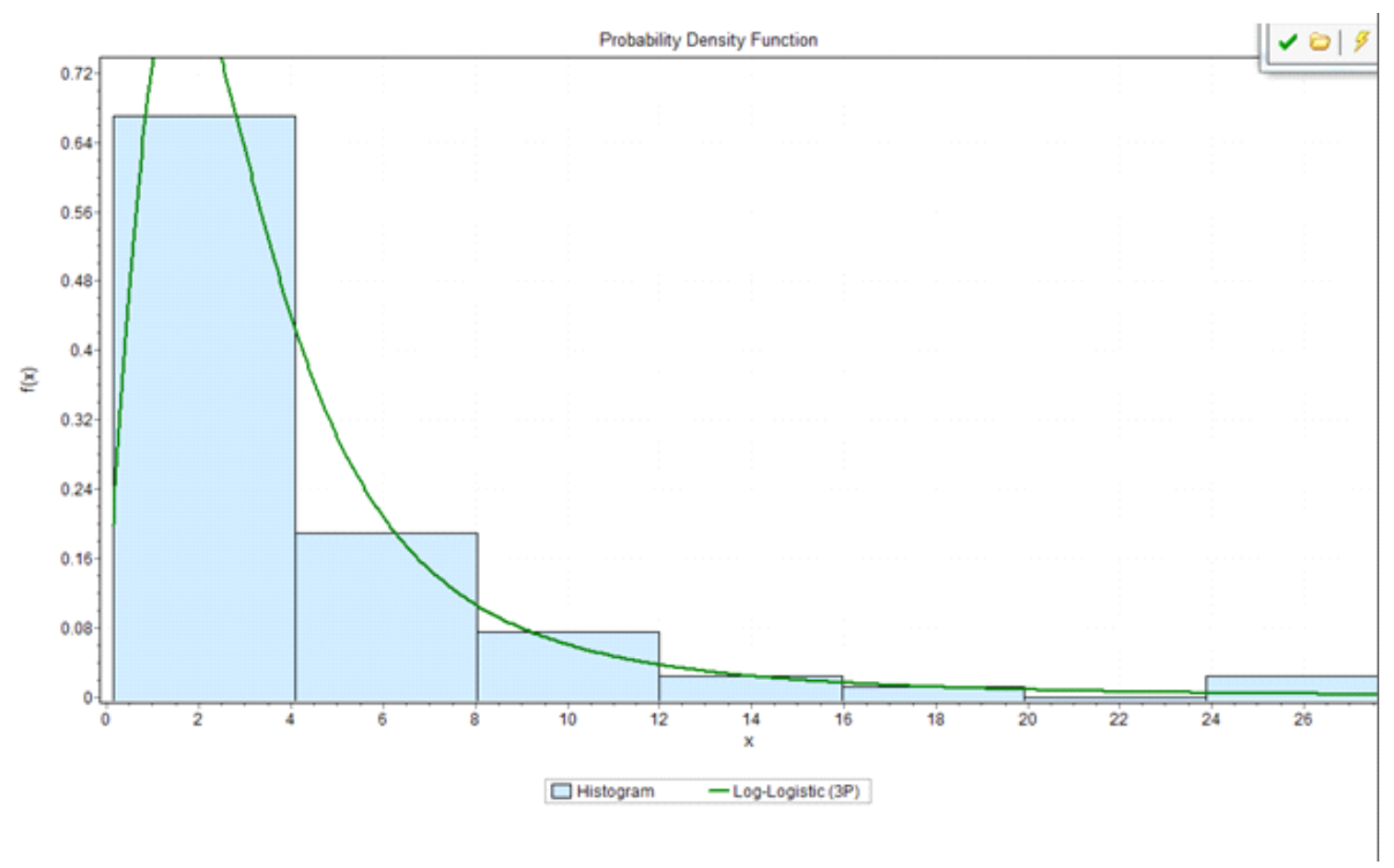

Graph1: log-logistic Distribution

\section{Characteristics and Limitations of the K-S Test:}

An attractive feature of this test is that the distribution of the K-S test statistic itself does not depend on the underlying cumulative distribution function being tested. Another advantage is that it is an exact test (the chi-square goodness-of-fit test depends on an adequate sample size for the approximations to be valid). Despite these advantages, the K-S test has several important limitations:

- It only applies to continuous distributions.

- It tends to be more sensitive near the centre of the distribution than at the tails.

- Perhaps the most serious limitation is that the distribution must be fully specified. That is, if location, scale, and shape parameters are estimated from the data, the critical region of the K-S test is no longer valid. It typically must be determined by simulation

Due to limitations 2 and 3 above, many analysts prefer to use the Anderson-Darling goodness-of-fit test. However, the Anderson-Darling test is only available for a few specific distributions. 


\section{Anderson-Darling test:}

\section{Test for Distributional Adequacy:}

The Anderson-Darling test (Stephens, 1974) is used to test if a sample of data came from a population with a specific distribution. It is a modification of the Kolmogorov-Smirnov (K-S) test and gives more weight to the tails than does the K-S test. The K-S test is distribution free in the sense that the critical values do not depend on the specific distribution being tested.

The Anderson-Darling test makes use of the specific distribution in calculating critical values. This has the advantage of allowing a more sensitive test and the disadvantage that critical values must be calculated for each distribution.

Example: Car-LMV combination

The best distribution followed by headways is Frechet (3P) in Anderson Darling test.

$$
\text { Goodness of Fit - Summary }
$$

\begin{tabular}{|c|l|c|c|c|c|c|c|}
\hline \multirow{2}{*}{$\#$} & \multirow{2}{*}{ Distribution } & \multicolumn{2}{c|}{$\begin{array}{c}\text { Kolmogorov } \\
\text { Smirnov }\end{array}$} & \multicolumn{2}{c|}{$\begin{array}{c}\text { Anderson } \\
\text { Darling }\end{array}$} & \multicolumn{2}{c|}{ Chi-Squared } \\
\cline { 3 - 8 } & Statistic & Rank & Statistic & Rank & Statistic & Rank \\
\hline 16 & Frechet (3P) & 0.04834 & 2 & 0.20898 & 1 & 3.0684 & 1 \\
\hline 19 & Gen. Extreme Value & 0.04841 & 3 & 0.21538 & 2 & 3.1446 & 2 \\
\hline 34 & Log-Logistic (3P) & 0.04736 & 1 & 0.2201 & 3 & 3.2264 & 3 \\
\hline 7 & Dagum & 0.05219 & 5 & 0.25107 & 4 & 4.8005 & 7 \\
\hline 3 & Burr (4P) & 0.05182 & 4 & 0.26112 & 5 & 4.791 & 6 \\
\hline 2 & Burr & 0.05292 & 6 & 0.26948 & 6 & 5.1359 & 9 \\
\hline 45 & Pearson 6 (4P) & 0.053 & 7 & 0.28323 & 7 & 5.2903 & 11 \\
\hline 8 & Dagum (4P) & 0.05962 & 9 & 0.29655 & 8 & 6.1644 & 17 \\
\hline 38 & Lognormal (3P) & 0.05798 & 8 & 0.34718 & 9 & 4.5411 & 5 \\
\hline 44 & Pearson 6 & 0.06278 & 10 & 0.36815 & 10 & 5.6823 & 12 \\
\hline
\end{tabular}

Table 4: Goodness of fit using Anderson-Darling test

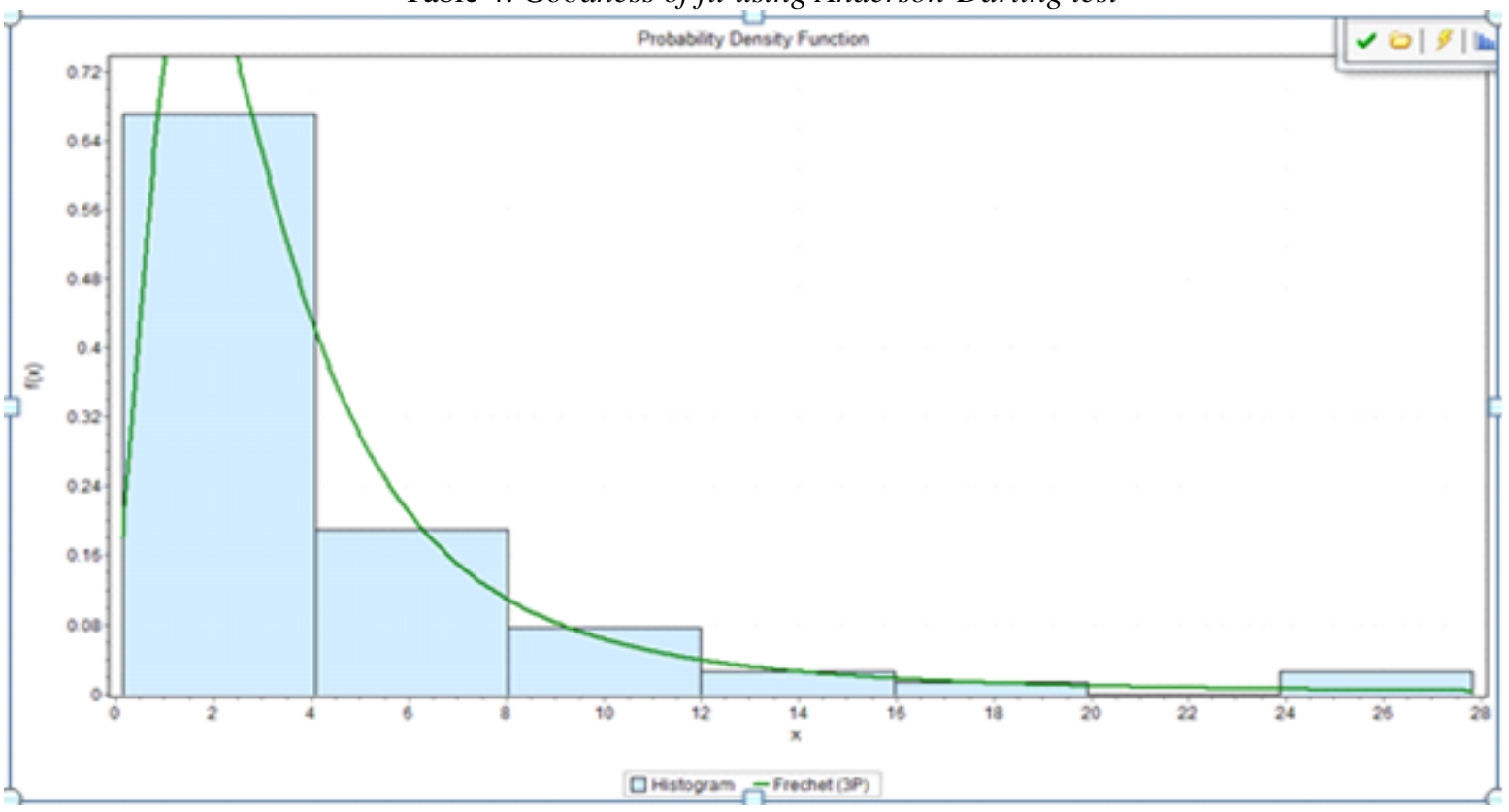

Graph2: Frechet (3P) Distribution

\section{Chi-Square Goodness-of-Fit Test}

The chi-square test (Snedecor and Cochran, 1989) is used to test if a sample of data came from a population with a specific distribution.

An attractive feature of the chi-square goodness-of-fit test is that it can be applied to any univariate distribution for which you can calculate the cumulative distribution function. 
The chi-square goodness-of-fit test can be applied to discrete distributions such as the binomial and the Poisson. The Kolmogorov-Smirnov and Anderson-Darling tests are restricted to continuous distributions.

Example: Car-LMV combination

The best distribution followed by headways is Frechet (3P) in Chi-square test.

\section{Goodness of Fit - Summary}

\begin{tabular}{|c|l|c|c|c|c|c|c|}
\hline \multirow{2}{*}{$\#$} & \multirow{2}{*}{ Distribution } & \multicolumn{2}{|c|}{$\begin{array}{c}\text { Kolmogorov } \\
\text { Smirnov }\end{array}$} & \multicolumn{2}{c|}{$\begin{array}{c}\text { Anderson } \\
\text { Darling }\end{array}$} & \multicolumn{2}{c|}{ Chi-Squared } \\
\cline { 3 - 8 } & & Statistic & Rank & Statistic & Rank & Statistic & Rank \\
\hline 16 & Frechet (3P) & 0.04834 & 2 & 0.20898 & 1 & 3.0684 & 1 \\
\hline 19 & Gen. Extreme Value & 0.04841 & 3 & 0.21538 & 2 & 3.1446 & 2 \\
\hline 34 & Log-Logistic (3P) & 0.04736 & 1 & 0.2201 & 3 & 3.2264 & 3 \\
\hline 7 & Dagum & 0.05219 & 5 & 0.25107 & 4 & 4.8005 & 7 \\
\hline 3 & Burr (4P) & 0.05182 & 4 & 0.26112 & 5 & 4.791 & 6 \\
\hline 2 & Burr & 0.05292 & 6 & 0.26948 & 6 & 5.1359 & 9 \\
\hline 45 & Pearson 6 (4P) & 0.053 & 7 & 0.28323 & 7 & 5.2903 & 11 \\
\hline 8 & Dagum (4P) & 0.05962 & 9 & 0.29655 & 8 & 6.1644 & 17 \\
\hline 38 & Lognormal (3P) & 0.05798 & 8 & 0.34718 & 9 & 4.5411 & 5 \\
\hline 44 & Pearson 6 & 0.06278 & 10 & 0.36815 & 10 & 5.6823 & 12 \\
\hline
\end{tabular}

Table 5: Goodness of fit using Chi-square test

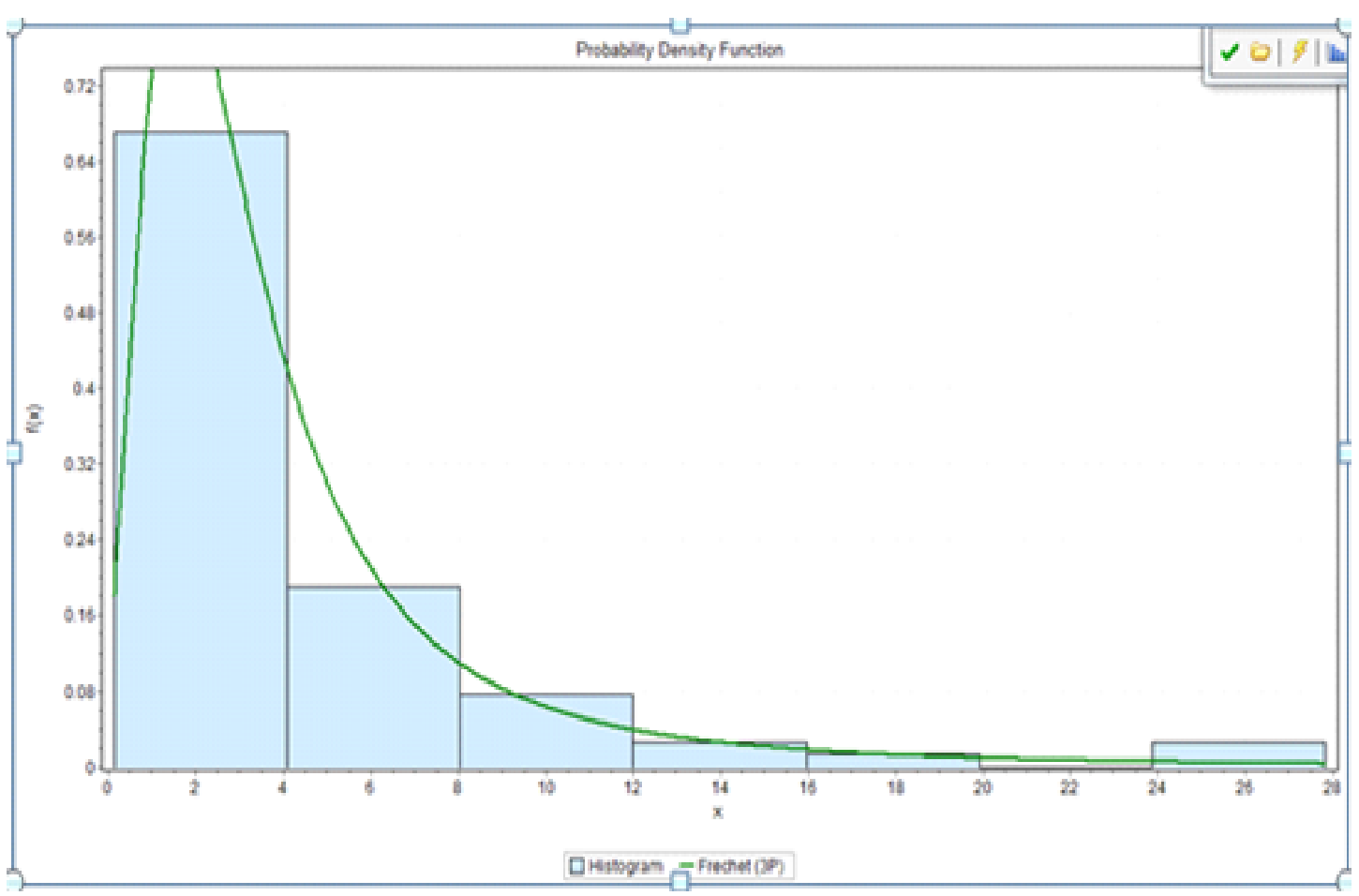

Graph 3: Frechet (3P) Distribution 
Table 6: Best fit distribution for 25 lead-lag vehicle pair headways

\begin{tabular}{|c|c|c|c|c|}
\hline \multirow[t]{2}{*}{ S.no } & \multirow[t]{2}{*}{ Lead-lag pair } & \multicolumn{3}{|c|}{ Best fit distribution } \\
\hline & & K-Smirnov & A-Darling & Chi-square \\
\hline 1 & $\mathrm{C}-\mathrm{C}$ & Fatigue life (3P) & Fatigue Life & Fatigue Life \\
\hline 2 & C-A & Gen. Pareto & Johnson SB & Beta \\
\hline 3 & C-LMV & Gen. Pareto & Gen. Pareto & Burr \\
\hline 4 & C-HMV & Log-Pearson3 & Log-Pearson3 & Log-Logistic (3P) \\
\hline 5 & C-TW & Log-Logistic (3P) & Frechet (3P) & Frechet (3P) \\
\hline 6 & A-TW & Johnson SB & Gen.Extreme Value & Beta \\
\hline 7 & A-LMV & Gumbel min & Johnson SB & Beta \\
\hline 8 & $\mathrm{~A}-\mathrm{C}$ & Gen.Extreme Value & Gen. Pareto & Reciprocal \\
\hline 9 & LMV-LMV & Gen. Pareto & Gen. Pareto & Lognormal \\
\hline 10 & LMV-HMV & Cauchy & Cauchy & Beta \\
\hline 11 & LMV-TW & Dagum & Dagum & Log-Pearson3 \\
\hline 12 & LMV-C & Dagum & Dagum & Pearson 6 \\
\hline 13 & HMV-TW & Gen.Extreme Value & Gen.Extreme Value & Beta \\
\hline 14 & HMV-C & Gen. Pareto & Log-Pearson3 & Erlang (3P) \\
\hline 15 & TW-A & Log-Pearson3 & Log-Pearson3 & Beta \\
\hline 16 & TW-C & Pareto 2 & Log-Pearson3 & Johnson SB \\
\hline 17 & TW-LMV & Dagum & Dagum & Lognormal \\
\hline 18 & TW-TW & Fatigue life (3P) & Log-Pearson3 & Fatigue life (3P) \\
\hline 19 & TW-HMV & Log-Pearson3 & Log-Pearson3 & Reciprocal \\
\hline 20 & LMV-A & Log-Logistic (3P) & Johnson SB & Beta \\
\hline 21 & A-A & no Distribution & no Distribution & no Distributon \\
\hline 22 & A-HMV & Follows no Distribution & $\begin{array}{ll}\text { Follows } & \text { no } \\
\text { Distribution } & \end{array}$ & Follows no Distribution \\
\hline 23 & HMV-A & NO distribution & no Distribution & no Distribution \\
\hline 24 & HMV-HMV & Follows no Distribution & $\begin{array}{ll}\text { Follows } & \text { no } \\
\text { Distribution } & \end{array}$ & Follows no Distribution \\
\hline 25 & HMV-LMV & no Distribution & no Distribution & no Distribution \\
\hline
\end{tabular}

A (Auto), C(Car), TW(Two wheeler), LMV(Low motorized vehicles)

\section{SPEED}

Speeds for all vehicle categories, lane wise and pair wise are calculated.

Speed $=$ Distance $/$ Headway

Table 7: Pair wise speeds

\begin{tabular}{|l|l|l|l|l|l|}
\hline S.NO & Lead-Lag Pair & \multirow{2}{*}{$\begin{array}{l}\text { No. } \\
\text { observations }\end{array}$} & & of & Speed $(\mathbf{m} / \mathbf{s e c})$ of Lead Vehicles \\
\cline { 4 - 6 } & & 28 & 0.51 & 12.5 & Average \\
\hline 1 & A-TW & 126 & 0.21 & 13.71 & 8.05 \\
\hline 2 & C-C & 16 & 1.16 & 14.25 & 6.75 \\
\hline 3 & C-A & 21 & 1.08 & 15.63 & 7.12 \\
\hline 4 & C-LMV & 8 & 1.27 & 10.87 & 7.26 \\
\hline 5 & C-HMV & 8 & & 4.73 \\
\hline
\end{tabular}

A(Auto), C(Car), TW(Two wheeler), LMV(Low motorized vehicles)

\section{SPEED-FLOW CURVE}

Speed flow diagrams are used to determine the speed at which the optimum flow occurs. As the volume increases, speed decreases. This plot trend can be used to find level-of-service and capacity (max. flow).

Expressing traffic volume as number of vehicles per lane per unit time will be inappropriate for the traffic conditions prevailing on Indian roads. The problem of measuring heterogeneous traffic flow has been addressed by converting the different types of vehicles into equivalent passenger cars and expressing the volume in terms of Passenger Car Unit (PCU) per hour. IRC-106 recommends below conversion factors. 
Table 8: Recommended Equivalent PCU factors (IRC 106: 1990)

\begin{tabular}{|c|c|c|}
\hline \multirow{2}{*}{ Vehicle type } & \multicolumn{2}{|c|}{ Equivalent PCU factors } \\
\cline { 2 - 3 } & \multicolumn{2}{|c|}{ Percentage composition of vehicle type in traffic stream } \\
\cline { 2 - 3 } & $5 \%$ & $10 \%$ and above \\
\hline Two wheelers Mortar cycle or & 0.5 & 0.75 \\
scooter etc. & & 1.0 \\
\hline Passenger car & 1.0 & 2.0 \\
\hline Auto-rickshaw & 1.2 & 2.0 \\
\hline Light commercial vehicle & 1.4 & 3.7 \\
\hline Truck or bus & 2.2 & \\
\hline
\end{tabular}

Table 9: One minute volume and Average speeds

\begin{tabular}{|c|c|c|c|}
\hline Duration & Volume(veh/min) & PCU/h & $\begin{array}{c}\text { Average Speed } \\
(\mathbf{k m} / \mathbf{h})\end{array}$ \\
\hline $5: 21-5.22$ & 48 & 3021 & 62.53 \\
\hline $5: 23-5.24$ & 48 & 2490 & 67.10 \\
\hline $5: 25-5.26$ & 43 & 2559 & 65.74 \\
\hline $5: 33-5.34$ & 54 & 2844 & 62.75 \\
\hline $5: 39-5.40$ & 48 & 3033 & 62.39 \\
\hline $5.59-6.00$ & 42 & 2661 & 63.18 \\
\hline
\end{tabular}

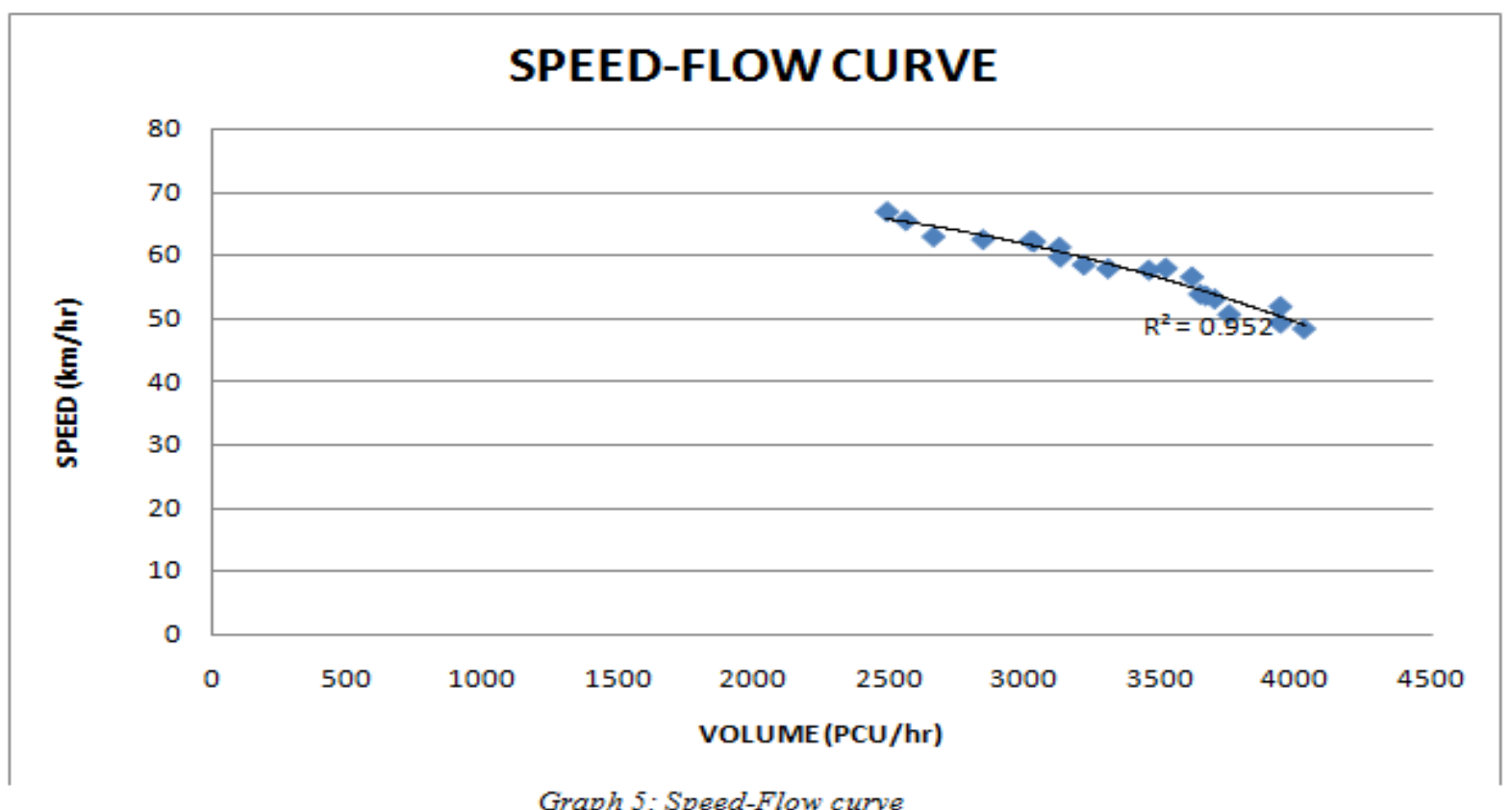

\section{LIMITATIONS}

1. The study was conducted only for one hour data which is insufficient to analyze and make a conclusion about its level of service.

2. No relationship or trend was observed from headway speed graph.

3. Due to limited data available, the speed flow curve was plotted by projecting one minute volume and average speeds. Some data points were excluded in order to obtain the standard relation.

\section{CONCLUSIONS}

Data was collected for a six lane divided two way roads in Chennai city and extracted for one hour by using Irfan View software. From this data set, speeds of vehicles and headways for pairs of vehicles were found out. Total combinations of different vehicle pairs were 25 . 
Of all the 25 different combinations, Auto-Auto, Auto-LMV, HMV-Auto, HMV-HMV and HMV-LMV pairs do not follow any distribution. The above mentioned pairs do not have minimum observations (i.e., $>7$ ) to fit into any distribution by using EASYFIT.

Speed-flow curves were along expected trends. However, since congested regimes were not reached during the observation periods, capacity values could not be estimated.

More case studies and data sets are necessary to obtain further insights on headways and flows.

\section{REFERENCES}

[1] Al-Ghamdi, A. S (2001). “Analysis of time headways on urban roads: Case study from Riyadh,” Journal of Transportation Engineering, ASCE, Vol. 127 ,pp. 289-294.

[2] Arasan, V. T. and R. Z. Koshy (2003). "Headway distribution of heterogeneous traffic on urban arterials," Journal of the Institution of Engineers (India), Vol. 84, pp. 210-214, 2003.

[3] Arasan, V. T. and S. S. Arkatkar (2011). "Microsimulation study of vehicular interactions in heterogeneous traffic flow on intercity roads," European Transport, Vol. 48, pp. 60-86.

[4] Chandra, S. and R. Kumar. (2001). " Headway modeling under mixed traffic on urban roads," Road Transport Research, Vol. 10, No.1, pp. 61-79.

[5] Cowan, R. J. (1975). "Useful headway models," Transportation Research, Vol. 9, No. 6, pp. 371-375.

[6] Griffiths, J. D. and J. G. Hunt (1991). "Vehicle headways in urban areas," Traffic Engineering and control, pp. 458-462.

[7] Hoogendoorn, S. and P. Bovy (1998). "A new estimation technique for vehicle-type specific headway distributions," Transportation Research Record, No. 1646, pp. 18-28.

[8] Indian Road Congress IRC: 106-1990. "Guide Lines for Capacity of Urban Roads in Plain Areas".

[9] Kadiyali, L. R. (2010). Fundamentals of traffic flow. Traffic Engineering and Transport planning, New Delhi, pp.553-559.

[10] Katti, B.K. and R. H. Pathak (1985). "A Study on Headway Distribution Models for the Urban Road Sections under Mixed Traffic Conditions," Highway Research Bulletin, Vol. 26, Indian Roads Congress, pp. 1-30.

[11] Kumar, V. M. and S. K. Rao (1998). "Headway and Speed Studies on Two-lane Highways," Indian Highways, Indian Roads Congress, Vol. 26, No.pp. 23-36.

[12] Luttinen, R.T. (1999). "Properties of cowan's M3 Headway Distribution," Transportation Research Record, No. 1678, TRB, National Research Council, Washington, D.C., pp. 189-196.

[13] May, A.D. (1990) Traffic Flow Fundamentals, Prentice Hall, Upper saddle River, N.J.

[14] Venkatesan, K. A. Gowri Asaithambi, K. K. Srinivasan and R. Sivanandan (2011) "Vehicle Classwise Analysis of Time Gaps and Headways under Heterogeneous Traffic", TRB Annual Meeting 2011, Washington D. C., USA. 